Working Paper 9505

\title{
DEBT AND EQUITY AS OPTIMAL CONTRACTS
}

by João Cabral dos Santos

João Cabral dos Santos is an economist at the Federal Reserve Bank of Cleveland. The author thanks Russell Cooper, Laurence Kotlikoff, Joseph Haubrich, James Thomson, and especially Douglas Gale for useful comments and suggestions. Financial support from Faculdade de Economia da Universidade Nova de Lisboa, Fundação Luso Americana para o Desenvolvimento, and Junta Nacional de Investigação Cientifíca e TecnológicaPrograma Ciência is gratefully acknowledged.

Working papers of the Federal Reserve Bank of Cleveland are preliminary materials circulated to stimulate discussion and critical comment. The views stated herein are those of the author and are not necessarily those of the Federal Reserve Bank of Cleveland or of the Board of Governors of the Federal Reserve System.

June 1995 


\begin{abstract}
The model presented in this paper is a particular case of the principal-agent problem. An entrepreneur has an investment project whose returns depend on his effort, which is not observable by the financier. After determining the optimal contract that is used to finance such a project, I show that this contract can be replicated by a unique combination of debt and equity, which proves the optimality of these financial instruments.
\end{abstract}


clevelandfed.org/research/workpaper/1995/wp9505.pdf 


\section{Introduction}

The security design literature has made important progress in the development of models in which debt is an optimal contract. Some have used an agency cost argument, as happens in Townsend (1979), Diamond (1984), and Gale and Hellwig (1985); others have used a principal-agent model, as happens in Hart and Moore (1989); and still others have used an adverse selection argument, as happens in Allen and Gale (1992). Important progress has also been made in the development of models in which equity is an optimal contract. Here, the most frequent explanation adopted has been corporate control, as happens in Grossman and Hart (1988) and Harris and Raviv (1988).

Some of these models-particularly those that show the optimality of debt using an agency cost argument-have become very popular for studying problems that involve the financial sector of the economy because of their flexibility and simplicity. However, the lack of an identical model in which both debt and equity are optimal contracts has made it difficult to address other issues, such as the implications of regulations that limit banks' investments in equity or whether these investments should be regulated differently from

banks' loans, and identification of the advantages of different banking structures. The importance of these questions has increased with the advent of universal banking structures in the European Community countries and with the ongoing discussion about the repeal of the Glass-Steagall Act in the United States.

There have been some attempts to derive the simultan eous optimality of debt and equity contracts, such as Chang (1987) and Williams (1989), but they are not without problems. Both use the same idea as Townsend (1979): Contracts cannot depend directly on the value of the firm's assets. In addition, these studies also assume that there exists in the firm one asset or part of its return that can be allocated to outsiders through a contract. In both cases, they claim that the optimal contract can be replicated by a combination of debt and equity. In fact, their optimal contracts have some similarities with these financial 
instruments, but the correspondence is not perfect. For example, in Chang's paper, the manager is the residual claimant of the firm instead of the equityholders. In Williams' model, the problem is that the face value of debt he uses to compute the payment to equityholders is different from the payment made to debtholders.

It is beyond the scope of this paper to present a general theory that explains the optimality of debt and equity contracts. Instead, the goal is to develop a model in which these instruments are optimal, and with a structure flexible enough to be incorporated in more general frameworks in order to address issues related to these contracts. ${ }^{1}$ This is accomplished using the following principle: If it is possible to reduce the number of variables that a manager can control to a space of dimension two then, in general, it will be possible to implement the second-best outcome through a combination of two financial instruments. ${ }^{2}$ This principle is considered in a principal-agent model where the agent has an investment project that produces an outcome in three states of nature. The moral hazard is generated by the dependence of the investment return in each state on the (unobservable) agent's effort.

Despite the limitations introduced by the existence of a restricted number of states of nature, the paper also shows some interesting comparative static results and insights as to why those financial instruments are optimal. In a more recent paper, Diamond (1995) uses a similar framework, that is, a principal-agent model with three states of nature, to study the optimal compensation scheme to be offered by the principal to the agent.

The paper proceeds as follows: In section 2, the model is introduced and in section 3 , the first-best solution is computed. In sections 4 and 5 , respectively, the optimal contract is determined and the optimality of debt and equity is shown. The conclusions are presented

\footnotetext{
${ }^{1}$ For a study of some banking regulations using this framework, see Santos (1995).

${ }^{2}$ Bester and Hellwig (1987) also use this principle in a principal-agent model to show the optimality of debt and equity contracts. However, the model presented here has two advantages: It allows the use of convex programming theory and it produces closed-form solutions.
} 
in section 6 , followed by an appendix that contains the proofs.

\section{The Model}

In the principal-agent model presented here, there is an entrepreneur, the agent, who has an investment project but does not have the necessary funds to finance it. As a result, he must obtain these funds from a financier, the principal. The moral hazard is generated by the dependence of the project's expected returns on the agent's effort, which is not observable by the principal.

The assumptions of the model are:

Assumption 1 The entrepreneur and the financier are both risk neutral. The entrepreneur has no funds, while the opportunity cost of the financier's capital, $i$, is exogenous to the model.

Assumption 2 The project has the following characteristics:

- it requires an initial investment equal to $\bar{I}$ and one period later it produces the total return $y_{i}$ with the probability $p_{i}$, and

- the number of possible returns of the project is finite. In particular, I assume that it has only three possible returns:

$$
y_{0}<y_{1}<y_{2}
$$

where $y_{0} \equiv 0$, and $y=\left\{y_{1}, y_{2}\right\}$

In this model, the probability distribution of the project's returns is assumed to be an endogenous variable because it depends on the entrepreneur's effort. Moreover, I also assume that the entrepreneur incurs a cost for each level of effort that he chooses.

One way to model this situation would be to take the entrepreneur's effort as the choice variable. In that case, it would be necessary to specify a functional relationship between the 
probabilities and the effort, and a cost function that would depend on the effort. Instead, I use a different approach wherein the choice variables are the probabilities themselves. Because the entrepreneur incurs a certain cost for each probability distribution that he chooses, in this approach the cost function depends on the probabilities $\left(p_{1}, p_{2}\right)$ with the convention that $p_{0} \equiv 1-\sum_{i=1}^{2} p_{i}$. The main advantage of this approach is that it avoids some of the technical difficulties that frequently appear when solving a principal-agent problem. $^{3}$ In addition, the choice of a cost function that is strictly convex and strictly increasing in its arguments makes it possible to use convex programming theory in solving the model.

Assumption 3 Let $C(\cdot)$ denote the cost function. Then

$$
C(p): p \longrightarrow R^{+}
$$

where $p=\left\{p_{1}, p_{2}\right\}$, and $C(\cdot)$ is $C^{2}$, strictly convex, strictly increasing and satisfies the condition $C(0)=0$. In particular, $I$ use the following cost function:

$$
C(p)=\frac{1}{2} a_{1} p_{1}^{2}+\frac{1}{2} a_{2} p_{2}^{2}+a_{3} p_{2}
$$

with $a_{j}>0$ for $j=1,2,3$.

A necessary condition to motivate the entrepreneur to choose a positive level of effort in state $1\left(p_{1}>0\right)$ is that $y_{1}>0$, which is part of assumption (1). However, with respect to state 2 , due to the linear term included in the cost function, in order to motivate the entrepreneur to choose $p_{2}>0$, it is necessary to assume the following:

\section{Assumption 4}

$$
y_{2}-a_{3}>0
$$

\footnotetext{
${ }^{3}$ For a discussion of the advantages associated with this approach, see Holmström (1979).
} 


\section{The First-Best Outcome}

The first--best outcome would be the solution to the model presented here if the financier could observe the level of effort chosen by the entrepreneur in each state, or if the entrepreneur had enough funds to finance the project. In both cases, this outcome would be the solution to the following problem: ${ }^{4}$

$$
\begin{aligned}
\underset{p}{\operatorname{Max}} & \Pi=p y-C(p)-\bar{I}(1+i) \\
\text { s.t. } & p e \leq 1 \\
& p \geq 0
\end{aligned}
$$

where $e$ is a vector of ones.

Because the objective function is $C^{2}$ and strictly concave in $p$, and the feasible set is convex and compact, we are in the presence of a convex programming problem. In this case, we know there is a unique optimum and that the Kuhn-Tucker conditions are necessary and sufficient for a solution.

Given that I am interested only in the situations where $p_{0}>0$ (when there is some risk of failure of the project), this implies that the constraint to the first-best problem is not binding and, as a result, the multiplier associated with it is zero. ${ }^{5}$ In this case, from the Kuhn-Tucker conditions one can immediately see that the first-best outcome to this problem is

$$
\begin{aligned}
& p_{1}^{f b}=\frac{y_{1}}{a_{1}}, \\
& p_{2}^{f b}=\frac{y_{2}-a_{3}}{a_{2}},
\end{aligned}
$$

\footnotetext{
${ }^{4}$ Note that in the case where the entrepreneur gets the funds from the financier and his effort is observable, the first-best outcome is the solution to that problem because $I$ assume that both the entrepreneur and the financier have transferable utilities. As a result, it is possible to maximize the sum of their payoffs.

${ }^{5}$ In order for this to be true, once the solution to this problem $\left(p_{1}^{f b}, p_{2}^{f b}\right)$ has been found, it is necessary to impose a condition on the parameters of the model such that $p_{1}^{f 6}+p_{2}^{f 6}<1$.
} 


$$
\Pi^{f b}=\frac{H}{2}-\bar{I}(1+i)
$$

where $\Pi^{f b}$ are the first-best profits of the project, and $H \equiv\left\{\frac{y_{1}^{2}}{a_{1}}+\frac{\left(y_{2}-a_{3}\right)^{2}}{a_{2}}\right\}$.

Assumptions (1) and (4) imply that $p_{1}^{f b}>0$ and $p_{2}^{f b}>0$. However, since these are probabilities, it is also necessary to make sure that their values are smaller than one. In addition, because of the initial condition that the project's probability of failure is strictly greater than zero, it is also necessary to have $p_{1}^{f b}+p_{2}^{f b}<1$. These new restrictions on the parameters of the model are summarized in the following assumption:

\section{Assumption 5}

$$
\begin{aligned}
& y_{1}<a_{1}, \\
& y_{2}-a_{3}<a_{2}, \\
& a_{1}\left(y_{2}-a_{3}\right)+a_{2} y_{1}<a_{1} a_{2} .
\end{aligned}
$$

\section{The Optimal Contract}

Suppose the entrepreneur does not have the necessary funds to undertake the project and that he will obtain them from a financier. Under these circumstances, even when the principal and the agent are both risk neutral, the first-best solution will not be reached. The well-known procedure that implements the first-best solution in this class of modelsthat is, the procedure whereby the principal demands a fixed payment and makes the agent the residual claimant-cannot be implemented here because in state 0 the project's outcome is zero and by assumption this state of nature occurs with a positive probability.

The contract that will rule the relationship between the financier and the entrepreneur must specify three items: First, the number of monetary units supplied by the financier to the entrepreneur at the beginning of the period; second, the probability distribution to be chosen by the entrepreneur; and, finally, the division of the project's returns that will occur at the end of the period. 
One thing that will become clear in this section is that the form of the optimal contract between the entrepreneur and the financier is independent of the relative market power that each has in his own sector. However, the same does not happen with respect to the revenue raised by that contract. Here, there exists a continuum of possibilities limited by the following two extremes. First, suppose that there are many entrepreneurs with identical projects but only one financier. In this case, the optimal contract will define a division of the returns that leaves to the entrepreneur only the absolute minimum needed to guarantee that he undertakes the project. Second, imagine now the opposite situation: perfect competition among the financiers. In this case, the optimal contract will give the financier only the required return to pay for the opportunity cost of the capital supplied to the entrepreneur at the beginning of the period.

Let $r_{i}$ be the payment required by the financier contingent on the return $y_{i}$. As a result of the limited liability condition, we have $r_{0} \equiv 0$ because by assumption $y_{0} \equiv 0$, and $r_{i} \leq y_{i}$ for $i=1,2$. Based on this definition, the contract between the two parties can be written as a triple $(\bar{I}, p, r)$, where $\bar{I}$ is the ṇumber of monetary units supplied by the financier, $p$ is the probability distribution chosen by the entrepreneur, and $r$ is the vector of (non-negative) contingent payments made by the entrepreneur.

The optimal contract that rules the relationship between the two parties is defined as the solution to the problem that maximizes the profits of the entrepreneur subject to the following constraints. The first are the incentive constraints, which are used to motivate the entrepreneur to choose the probability distribution $p$ given the payment schedule $r$ defined in the contract. ${ }^{6}$ The second is the participation constraint, which is used to guarantee that

\footnotetext{
${ }^{6}$ Note that even though the contract specifies a probability distribution, $p$, the entrepreneur cannot be forced to choose it because the effort that he puts into the project, which determines the probability distribution, is not observable by the financier. Hence, it is through these constraints that the financier can find the right incentive to give the entrepreneur in order to make him choose (voluntarily) a certain probability distribution.
} 
the financier's profits are at least equal to the minimum required by him. The third is the limited liability condition.

Proposition 1 The optimal contract to the problem defined here is $\left(\bar{I}, p^{*}, r^{*}\right)$, where

$$
\begin{aligned}
p^{*} & =\left[1-\left(\frac{y_{1}}{a_{1}}+\frac{y_{2}-a_{3}}{a_{2}}\right) f\left(\lambda^{*}\right), \frac{y_{1}}{a_{1}} f\left(\lambda^{*}\right), \frac{y_{2}-a_{3}}{a_{2}} f\left(\lambda^{*}\right)\right], \\
r^{*} & =\left[0, y_{1} f\left(\lambda^{*}\right),\left(y_{2}-a_{3}\right) f\left(\lambda^{*}\right)\right], \\
\text { with } & \begin{aligned}
f(\lambda) & =\frac{1-\lambda}{1-2 \lambda}, \\
\lambda^{*} & =\frac{1}{2}-\frac{1}{2} \sqrt{\frac{H}{H-4\left[\bar{I}(1+i)+\bar{\Pi}_{F}\right]}},
\end{aligned}
\end{aligned}
$$

and $\bar{\Pi}_{F}$ are the profits required by the financier with $0 \leq \bar{\Pi}_{F} \leq \frac{H}{4}-\bar{I}(1+i)$.

The formal proof of this proposition is in the appendix.

Looking at the results of this proposition, we see that $f(\cdot)$ is a decreasing and strictly concave function of $\bar{\Pi}_{F}$ in the relevant interval. As a result, when the profits required by the financier increase (suppose $\bar{\Pi}_{F}$ increases at a constant rate):

(a) the functional form of the optimal contract does not change;

(b) the entrepreneur's payments to the financier in each state $\left(r_{1}^{*}, r_{2}^{*}\right)$ increase;

(c) the probabilities of the project's positive outcomes $\left(p_{1}^{*}, p_{2}^{*}\right)$ decrease, while its probability of failure $\left(p_{0}^{*}\right)$ increases;

(d) the entrepreneur's profits $\left(\Pi_{E}^{*}\right)$ decrease;

(e) all the variations in these variables occur at an increasing rate.

This process can continue until the point equivalent to the existence of a monopoly in the financing sector. At that time, the financier gets the maximum amount of profits, which is equal to $\bar{\Pi}_{F}^{m}=\frac{H}{4}-\bar{I}(1+i)$. 
Comparing the first-best and the second-best solutions, we see that in the first case the project would be undertaken if $H>2 I(1+i)$. However, proposition (1) requires $H>$ $4 I(1+i)$ for the same project to be financed by an outsider. These conditions indicate that there is a set of projects that would be undertaken in the first-best case, but that these projects will not be financed by an outside party. This underinvestment represents one of the costs associated with the second-best outcome. In terms of the set of projects that would be undertaken in both situations, the results in proposition (1) show that in the second-best case, the probability of positive outcomes is always lower-that is, there is a generalized decrease in the entrepreneur's effort when he gets the funds from an outside source. This implies that in the second-best outcome, the project's probability of failure is always higher than in the first-best; furthermore, this difference increases as the profits required by the financier rise.

\section{Debt and Equity as Optimal Contracts}

Using a spanning argument, this section shows that debt and equity are optimal contracts in the model adopted in this paper. In addition, it presents some comparative static results and an explanation for the optimality of these financial instruments.

Suppose the financier decides to use debt and/or equity to finance the project. Then the new contract can be written as $(\bar{I}, p, \alpha, d)$, where $\bar{I}$ and $p$ have the same definition as before, $\alpha$ is the proportion of the firm's equity held by the financier, $(1-\alpha)$ is the proportion of the firm's equity held by the entrepreneur, and $d$ is the face value of debt borrowed by the entrepreneur. As usual, I assume that equityholders are the residual claimants and that they are protected by limited liability.

In addition to assumptions (1) to (5), I also assume that the constant marginal profits of the entrepreneur's effort before the payment to the financier are higher in state $2,\left(y_{2}-a_{3}\right)$, 
than in state $1,\left(y_{1}\right){ }^{7}$

\section{Assumption 6}

$$
y_{2}-a_{3}-y_{1}>0
$$

Proposition 2 The optimal contract defined in proposition (1) can be replicated by a unique combination of debt and equity, that is, by the contract $\left(\bar{I}, p^{*}, \alpha^{*}, d^{*}\right)$, where

$$
\begin{aligned}
\alpha^{*} & =\frac{\left(y_{2}-a_{3}-y_{1}\right) \lambda^{*}}{\left(y_{1}-y_{2}\right)\left(1-2 \lambda^{*}\right)}, \\
d^{*} & =\frac{a_{3} y_{1} \lambda^{*}}{\left(y_{1}-y_{2}\right)\left(1-\lambda^{*}\right)+a_{3} \lambda^{*}},
\end{aligned}
$$

and where $p^{*}$ and $\lambda^{*}$ are equal to the values presented in proposition (1).

A formal proof of this proposition is contained in the appendix. It is based on the following spanning argument: If there exists a feasible and unique combination of $\alpha$ and $d$ that motivates the entrepreneur to choose the second-best outcome $p^{*}$ and at the same time generates the same revenue to the bank as $r^{*}$, then it must be the case that debt and equity are optimal contracts in the model presented here.

Before presenting the intuition for the optimality of debt and equity, which will become more clear when I study how the optimal contract changes with variations in the assumptions of the model, I first present some comparative static results associated with proposition (2).

Using the functional forms of both $\alpha^{*}$ and $d^{*}$ and taking into consideration the fact that $\lambda^{*}=\lambda\left(y_{i}, a_{j}, \bar{I}, \bar{\Pi}_{F}\right)$ with $i=1,2$ and $j=1,2,3$, it is possible to show the following signs for the partial derivatives:

$$
\begin{aligned}
& \alpha^{*}=\alpha\left(\underset{-\underset{+}{y_{i}}, a_{j}, \bar{I}, \bar{\Pi}_{F}}{-+},\right. \\
& d^{*}=d\left(\underset{+}{y_{i}, a_{j+}, \vec{I}, \bar{\Pi}_{F}}\right) .
\end{aligned}
$$

\footnotetext{
${ }^{7}$ Note that, besides the constant part of the marginal profits of the entrepreneur's effort in each state of nature, there is also the marginal cost, which depends on the level of effort he chooses-that is, $a_{1} p_{1}$ and $a_{2} p_{2}$ for states 1 and 2, respectively. All of these values are obtained through the differentiation of the entrepreneur's profits before the payments to the financier $\left[p_{1} y_{1}+p_{2} y_{2}-C(p)\right]$ with respect to $p_{1}$ and $p_{2}$.
} 
The explanation for the negative relation between the optimal value of the financial instruments and the outcomes of the project is that when $y_{i}$ increases, the financier gets more revenue through his participation in the equity of the firm. In addition, an increase in the outcomes of the project motivates the entrepreneur to choose a higher level of effort, $p_{1}^{*}$ and $p_{2}^{*}$. As a result, it is possible for the financier to obtain the same expected profit, $\bar{\Pi}_{F}$, by holding less equity and charging a lower face value of debt.

The justification for the positive relation between the financial instruments and the parameters $a_{j}$ is that an increase in one of these parameters means an increase in the entrepreneur's cost of effort, which implies a decrease in the level of effort that he chooses. Then, in order to get the same expected level of profits, the financier must increase the revenue he collects both through his participation as an equityholder and through the face value of debt he charges to the entrepreneur.

Finally, in order to increase his profits, the financier increases both his participation in the firm's equity and the face value of debt. Furthermore, it is possible to show that as the profits required by the financier increase, the proportion of equity that he holds relative to the face value of debt decreases-that is,

$$
\frac{\alpha^{*}}{d^{*}}=g\left(\bar{\Pi}_{F}\right)
$$

This occurs because the level of effort that the entrepreneur puts into the project is more sensitive to the proportion of equity he holds than to the face value of debt he has to pay. Knowing this, when the financier wants to increase his profits, he increases the value of both financial instruments but increases the value of debt more than equity.

Let's see now what happens to the optimal contract when some variants of the model are considered. For example, suppose that assumption (6) is replaced by $y_{2}-a_{3}-y_{1}=0$. In this case, there would be no change to the optimal contract $\left(\bar{I}, p^{*}, r^{*}\right)$. However, now this contract can be replicated using only debt- that is, through $\left(\bar{I}, p^{*}, d^{\prime}\right)$, where

$$
d^{\prime}=\left(y_{2}-a_{3}\right)\left(\frac{\lambda^{*}}{2 \lambda^{*}-1}\right)
$$


Note that, despite the equality across states of the constant marginal profits of the entrepreneur's effort before the payment to the financier, $\left(y_{2}-a_{3}=y_{1}\right)$, equity does not replicate the optimal contract, because it does not take into account the entrepreneur's effort cost in state $2,\left(a_{3}\right)$. If equity were to be used here, since it would be a percentage of the project returns $y_{1}$ and $y_{2}$, it would penalize the entrepreneur in state 2 . As a result, he would choose a lower level of effort in this state. Because of the equality of the constant marginal profits of the entrepreneur's effort across states, the optimum outcome is reached by making him pay to the financier a value that is independent of the project's returns. That's why debt alone replicates the optimal contract in this example.

Going back to the original model, suppose now that $a_{3}=0$ (the constant marginal cost of the entrepreneur's effort in state 2 is eliminated). In this case, the optimal contract would be determined by the results in proposition (1) with $a_{3}=0$. It is possible to show that this contract can be replicated using only equity-that is, through $\left(\bar{I}, p^{*}, \alpha^{\prime}\right)$, where

$$
\alpha^{\prime}=\frac{\lambda^{\prime}}{2 \lambda^{\prime}-1}
$$

with $\lambda^{\prime}$ equal to $\lambda^{*}$ when $a_{3}=0$.

Note that the constant marginal profits of the entrepreneur's effort are now higher in state 2 than in state $1\left(y_{2}>y_{1}\right)$. In this situation, debt does not replicate the optimal contract because it does not take into account that difference. As a result, if debt were used, it would penalize the entrepreneur in state 1, making him choose a lower level of effort in this state. However, this problem is avoided if, instead, equity is used. Since there are no constant marginal costs (by assumption $a_{3}=0$ ), this financial instrument alone replicates the optimal contract.

From these two variants it becomes clear why a combination of debt and equity must be used in order to span the optimal contract in the initial model. The debt component of the contract is explained by the constant marginal cost of the entrepreneur's effort in state 2. Its existence is necessary in order to avoid penalizing the entrepreneur relatively more 
in this state than in state 1 . With respect to the equity component, its presence is justified by the difference of the project returns across states. Its existence is important so that the entrepreneur is not relatively more penalized in state 1, which has a lower return.

\section{Conclusion}

This paper shows the simultaneous optimality of debt and equity contracts by using the following principle: If for some reason, such as technological constraints, it is possible to reduce all of the variables (actions) that the manager can control to a space of dimension two then, in general, it will be possible to implement the second-best outcome through a combination of two financial instruments. This principle is incorporated in a principal-agent model where the agent has an investment project that produces an outcome in three states of nature. ${ }^{8}$ The return on this investment in each state depends on the (unobservable) effort chosen by the agent.

After deriving the optimal contract that the principal uses to finance the agent, I show that this contract can be spanned by a unique combination of debt and equity. The debt part of the contract is explained by the agent's (constant) cost of effort that affects the project's return in one of the states, while the equity component is explained by the difference of the return of the agent's effort across states of nature.

\footnotetext{
${ }^{8}$ For some interesting results about optimal compensation schemes in a similar framework, see Diamond (1995).
} 


\section{A Appendix}

\section{A.1 Proof of Proposition 1}

In order to prove this proposition, it is necessary to solve a principal-agent problem, which I do using a two-step procedure. ${ }^{9}$ In the first step, the incentive constraints are determined. In the second step, the profits of the entrepreneur are maximized over the set of implementable choices of $p$.

\section{A.1.1 First Step-The Entrepreneur's Problem}

For a given payment schedule $\bar{r}$, the entrepreneur must solve the following problem:

$$
\begin{aligned}
\underset{p}{\operatorname{Max}} & \Pi_{E}=p_{1}\left(y_{1}-\bar{r}_{1}\right)+p_{2}\left(y_{2}-\bar{r}_{2}\right)-C(p) \\
\text { s.t. } & p e \leq 1 \\
& p \geq 0 .
\end{aligned}
$$

Because the objective function is strictly concave and the feasible set is convex and compact, this is a convex programming problem with a unique solution. Moreover, the Kuhn-Tucker conditions are necessary and sufficient for a solution. Once again, I assume that the parameters of the model are such that $p_{0}>0$.

Taking into account the Kuhn-Tucker conditions and the existence of limited liability, it is possible to conclude that

(a) If $\bar{r}_{1}<y_{1}$, then $p_{1}>0$, and if $\bar{r}_{1}=y_{1}$, then $p_{1}=0$.

(b) If $\bar{r}_{2}<y_{2}-a_{3}$, then $p_{2}>0$, and if $y_{2}-a_{3} \leq \bar{r}_{2} \leq y_{2}$, then $p_{2}=0$.

\footnotetext{
${ }^{9}$ This procedure, which is known in the literature as the "first-order approach" to the principal-agent problem, is not valid in certain cases. See, for example, Mirrlees (1975). However, there are other cases where it is valid; for example, Rogerson (1985) and Jewitt (1988). In the present example, as I will argue, the first-order approach works without any problem.
} 
Moreover, it can be argued that it will never be optimal for the financier to choose $r_{1}=y_{1}$ and $y_{2}-a_{3} \leq r_{2} \leq y_{2}$ because these choices will generate no revenue for him. As a result, the incentive constraints for the case where $p_{1}+p_{2}<1$ are

$$
\begin{aligned}
y_{1}-r_{1}-a_{1} p_{1} & =0, \\
y_{2}-a_{3}-r_{2}-a_{2} p_{2} & =0 .
\end{aligned}
$$

Given that there is a one-to-one relation between $r_{1}$ and $p_{1}$ on the one hand, and between $r_{2}$ and $p_{2}$ on the other hand, then all the relevant probability distributions can be generated by the contracts that satisfy the incentive constraints. As a result, when solving the present model, it is sufficient to consider the set of contracts that satisfies these constraints.

\section{A.1.2 Second Step-The Financier's Problem}

In this step, the entrepreneur's profits are maximized over the set of implementable choices of $p$. This set is defined by the incentive constraints, the financier's participation constraint, and the limited liability condition. The idea behind this step is that given the profits required by financiers, $\bar{\Pi}_{F}$, they compete in order to offer the best feasible contract to the entrepreneur. The problem that a financier must solve can be formalized as follows:

$$
\begin{array}{ll}
\underset{r_{1}, r_{2}}{M a x} & \Pi_{E}=p_{1}\left(y_{1}-r_{1}\right)+p_{2}\left(y_{2}-r_{2}\right)-C(p) \\
\text { s.t. } & y_{1}-r_{1}-a_{1} p_{1}=0 \\
& y_{2}-a_{3}-r_{2}-a_{2} p_{2}=0 \\
& p_{1} r_{1}+p_{2} r_{2}-\bar{I}(1+i) \geq \bar{\Pi}_{F} \\
& 0 \leq r_{i} \leq y_{i} \quad \text { for } \quad i=1,2 .
\end{array}
$$

Note that by changing the profits required by the financier in the participation constraint (between zero, which occurs when there is perfect competition to finance the project, and the maximum amount of profits that he can get, $\left[\frac{H}{4}-\bar{I}(1+i)\right]$, which occurs when there is only 
one financier and many identical entrepreneurs), it is possible to find all of the admissible divisions of the project's returns between the entrepreneur and the financier, and all of the efficient contracts. In the process of finding all of these divisions, it is necessary to ensure that the entrepreneur's profits are sufficient to cover his opportunity cost of undertaking the project, which I assume to be zero. ${ }^{10}$ Furthermore, since the incentive constraints were derived under the assumption that $p_{i}>0$ for $i=0,1,2$, then the solution to the problem presented here must satisfy these initial conditions.

To solve this problem, I use two simplifications. First, I use the one-to-one relation that exists between $r_{i}$ and $p_{i}$ in the incentive constraints in order to rewrite the problem as a function of $p_{i}$. Second, it is clear that the financier's participation constraint will be verified exactly. If not, the entrepreneur's profits could be increased simply by offering him a new contract with a lower $r_{i}$. Therefore, I can "add" the financier's participation constraint to the objective function without altering the solution to the problem. Using these simplifications, I can write the problem as

$$
\begin{aligned}
\underset{p}{M a x} & \Pi_{E}=p_{1} y_{1}+p_{2} y_{2}-C(p)-\bar{I}(1+i)-\bar{\Pi}_{F} \\
\text { s.t. } & p_{1}\left(y_{1}-a_{1} p_{1}\right)+p_{2}\left(y_{2}-a_{3}-a_{2} p_{2}\right)-\bar{I}(1+i) \geq \bar{\Pi}_{F} \\
& p \geq 0 .
\end{aligned}
$$

Given that the objective function is strictly concave and the feasible set is compact and convex (the constraint is strictly concave), then we are again in the presence of a convex programming problem and the usual results apply. Defining $\lambda$ as the Lagrange multiplier, it is possible to argue that its value is strictly smaller than zero, in which case the solution

\footnotetext{
${ }^{10}$ In this step, it would have been possible to formalize the following different problem: Maximize the financier's profits subject to the entrepreneur's incentive constraints, the limited liability condition, and a constraint that would consider the profits required by the entrepreneur. In this case, the set of all possible divisions of the project returns would be obtained by changing the amount of profits required by the entrepreneur between its minimum, which occurs when there is a monopolist financier, and its maximum, which accurs when there is perfect competition among the financiers.
} 
to the present problem is the result in proposition (1), and all of the initial conditions that were assumed $\left(p_{i}>0\right.$ for $\left.i=0,1,2\right)$ are verified. ${ }^{11}$

\section{A.2 Proof of Proposition 2}

\section{A.2.1 First Step-The Entrepreneur's Problem}

For a given percentage of equity held by the financier, $\bar{\alpha}$, and a given face value of debt, $\bar{d}$, the entrepreneur must solve the following problem:

$$
\begin{aligned}
\underset{p}{M a x} & \Pi_{E}=p_{1}(1-\bar{\alpha})\left(y_{1}-\bar{d}\right)+p_{2}(1-\bar{\alpha})\left(y_{2}-\bar{d}\right)-C(p) \\
\text { s.t. } & p e \leq 1 \\
& p \geq 0 .
\end{aligned}
$$

Once again, this is a convex programming problem, so the usual results apply. For the case where $p_{i}>0$ for $i=0,1,2$ the incentive constraints are

$$
\begin{aligned}
(1-\alpha)\left(y_{1}-d\right)-a_{1} p_{1} & =0 \\
(1-\alpha)\left(y_{2}-d\right)-a_{3}-a_{2} p_{2} & =0
\end{aligned}
$$

\section{A.2.2 Second Step-The Financier's Problem}

Instead of defining the equivalent to the problem characterized in this step in the previous proof and showing that its solution is the result of proposition (2), I use a different approach here based on a spanning argument. The idea is as follows: If it is possible to find a feasible combination of $\alpha$ and $d$ that motivates the entrepreneur, through the incentive constraints,

\footnotetext{
${ }^{11}$ Implicit here is the following Lagrangean:
}

$$
\begin{aligned}
L(p, \lambda)= & p_{1} y_{1}+p_{2} y_{2}-C(p)-\bar{I}(1+i)-\bar{\Pi}_{F} \\
& +\lambda\left[\bar{\Pi}_{F}+\bar{I}(1+i)-p_{1}\left(y_{1}-a_{1} p_{1}\right)-p_{2}\left(y_{2}-a_{3}-a_{2} p_{2}\right)\right],
\end{aligned}
$$

where $\lambda \leq 0$. If $\lambda=0$ we would have the first-best solution but the constraint to this problem would not be verified. As a result, we need to have $\lambda<0$. 
to choose the probability distribution $p^{*}$, then the initial conditions are verified-that is, $p_{i}>0$ for $i=0,1,2$. In addition, if such a combination generates the same revenue to the financier as $r^{*}$ does, then it must be the solution to the financier's problem and, as a result, it is proven that the optimal contract can be spanned by a combination of debt and equity. From the incentive constraints and the second-best probability distribution $p^{*}$, I find $\alpha^{*}$ and $d^{*}$, the values that the financier would have to choose in order to implement $p^{*}$. Since these values satisfy the initial conditions that I have assumed, the last thing left to be proved is that the combination $\left(\alpha^{*}, d^{*}\right)$ generates the same revenue to the financier as $r^{*}$ does. This is apparent immediately once the following definitions are considered:

$$
\begin{aligned}
& r_{1}=\alpha\left(y_{1}-d\right)+d \\
& r_{2}=\alpha\left(y_{2}-d\right)+d
\end{aligned}
$$

which finishes the proof of proposition (2). 


\section{References}

Allen, F. and Gale, D. (1992). "Measurement Distortion and Missing Contingencies in Optimal Contracts," Economic Theory 2, 1-26.

Bester, H. and Hellwig, M. (1987). "Moral Hazard and Equilibrium Credit Rationing: An Overview of the Issues," in Agency Theory, Information and Incentives (G. Bamberg, and K. Spremenn, Eds.), pp. 135-166. Springer Verlag, Berlin.

Chang, C. (1987). "Capital Structure as Optimal Contracts," mimeo, University of Minnesota.

Diamond, D. (1984). "Financial Intermediation and Delegated Monitoring," Review of Economic Studies 51, 393-414.

Diamond, P. (1995). "Managerial Incentives: On the Near Optimality of Linearity," working paper, Massachusetts Institute of Technology.

Gale, D., and Hellwig, M. (1985). "Incentive Compatible Debt Contracts: The One-Period Problem," Review of Economic Studies 52, 647-663.

Grossman, S. J., and Hart, O. (1988). "One Share-One Vote and the Market for the Corporate Control," Journal of Financial Economics 20, 175-202.

Harris, M., and Raviv, A. (1988). "Corporate Governance: Voting Rights and Majority Rules," Journal of Financial Economics 20, 203-235.

Hart, O., and Moore, J. (1989). "Default and Renegotiation: A Dynamic Model of Debt," mimeo, Massachusetts Institute of Technology.

Holmström, B. (1979). "Moral Hazard and Observability," Bell Journal of Economics 10, $74-91$.

Jewitt, I. (1988). "Justifying the First Order Approach to the Principal Agent Problem," Econometrica 56, 1177-1190. 
Mirrlees, J. (1975). "The Theory of Moral Hazard and Unobservable Behavior-Part I," mimeo, Nuffield College.

Rogerson, W. (1985). "The First Order Approach to the Principal Agent Problem," Econometrica 53, 1357-1367.

Santos, J. C. (1995). "Banking Regulation: An Efficiency and Welfare Analysis," unpublished dissertation, Boston University.

Townsend, R. (1979). "Optimal Contracts and Competitive Markets with Costly State Verification," Journal of Economic Theory 21, 265-293.

Williams, S. (1989). "Ex-Ante Monitoring, Ex-Post Asymmetry, and Optimal Securities," working paper, University of British Columbia. 